\title{
Carbon dioxide insufflation reduces residual gas in the gastrointestinal tract following colorectal endoscopic submucosal dissection
}

\author{
TOMOHIKO SUGIYAMA, HIROSHI ARAKI, NORITAKA OZAWA, JUN TAKADA, \\ MASAYA KUBOTA, TAKASHI IBUKA and MASAHITO SHIMIZU
}

Department of Gastroenterology/Internal Medicine, Gifu University Graduate School of Medicine, Gifu 501-1194, Japan

Received November 28, 2017; Accepted January 10, 2018

DOI: $10.3892 /$ br.2018.1044

\begin{abstract}
Quantitative examinations evaluating the effects of $\mathrm{CO}_{2}$ insufflation on residual gas in the gastrointestinal tract following colorectal endoscopic submucosal dissection (ESD) are lacking. The present study aimed to assess whether $\mathrm{CO}_{2}$ insufflation could decrease the amount of residual gas in the gastrointestinal tract following ESD in patients with colorectal neoplasms. Computed tomography (CT) was used to objectively examine whether $\mathrm{CO}_{2}$ insufflation during colorectal ESD reduced residual gas levels in the gastrointestinal tract following ESD. A total of 83 patients who underwent colorectal ESD between January and December 2009 at Gifu University Hospital (Gifu, Japan) were enrolled. Following exclusion of 17 patients with chronic pulmonary dysfunction, 66 patients were randomized into a $\mathrm{CO}_{2}$ insufflation group $(\mathrm{n}=34)$ and an air insufflation group $(n=32)$. The level of residual gas and the presence of transmural and free-air leaks following ESD were evaluated in both groups using CT. Transcutaneous $\mathrm{CO}_{2}$ tension $\left(\mathrm{PtcCO}_{2}\right)$ and ESD-related complications were also compared between the groups. CT measurements of the major and minor axes of the cecal lumen, and of the terminal ileum diameter, indicated the level of residual gas following ESD to be significantly reduced in the $\mathrm{CO}_{2}$ insufflation group compared with the air insufflation group $(\mathrm{P}<0.001)$. Neither the incidences of ESD-related complications, including post-procedure hemorrhage and air leak, nor the abnormalities in vital signs differed between the groups. No significant between-group differences were identified in the baseline and peak $\mathrm{PtcCO}_{2}$ levels during $\mathrm{ESD}$ or in the median $\mathrm{PtcCO}_{2}$ following ESD. In conclusion, $\mathrm{CO}_{2}$ insufflation during colorectal ESD was effective in reducing residual gas in the gastrointestinal tract following ESD.
\end{abstract}

Correspondence to: Dr Hiroshi Araki, Department of Gastroenterology/Internal Medicine, Gifu University Graduate School of Medicine, 1-1 Yanagido, Gifu, Gifu 501-1194, Japan E-mail: araara@gifu-u.ac.jp

Key words: carbon dioxide, colorectal endoscopic submucosal dissection, computed tomography, insufflation, residual gas

\section{Introduction}

Colorectal cancer is among the most prevalent malignancies worldwide, and therefore effective and minimally invasive procedures are required to reduce the incidence rate of this malignancy $(1,2)$. More recently, utilization of colorectal endoscopic submucosal dissection (ESD) as a minimally invasive treatment for en bloc resection of large superficial neoplasms has become a favored method (3). However, the risk of complication is higher than in gastric ESD as the wall of the colon is thin and operability is limited. In addition, colorectal ESD generally requires a long procedure time due to its technical difficulty (4,5). Therefore, a high level of gas enters the colonic lumen. This is associated with aggravation of subjective symptoms, such as abdominal pain, discomfort and distention, and an increased risk of severe problems, including pneumoderma, pneumothorax, abdominal compartment syndrome and air embolism (6-14).

The safety and efficacy of $\mathrm{CO}_{2}$ insufflation during ESD for lesions of the esophagus and stomach have been demonstrated in several randomized controlled trials (15-21). A pilot study also reported that $\mathrm{CO}_{2}$ insufflation was safe and effective during colorectal ESD (15). As $\mathrm{CO}_{2}$ is absorbed faster than air and is rapidly eliminated through the lungs, $\mathrm{CO}_{2}$ insufflation is expected to reduce residual gas in both the small and large bowels following ESD, and consequently reduce the abdominal symptoms and complications associated with ESD (15,22-30). However, to the best of our knowledge, detailed and quantitative examinations evaluating the effects of $\mathrm{CO}_{2}$ insufflation on residual gas in the gastrointestinal tract following colorectal ESD have not been performed.

The aim of the present study was to assess whether $\mathrm{CO}_{2}$ insufflation could decrease the level of residual gas in the gastrointestinal tract following ESD in patients with colorectal neoplasms. All patients received an abdominal computed tomography (CT) examination immediately following colorectal ESD, and the level of residual gas in the gastrointestinal tract following ESD was objectively evaluated by measuring the axes of the cecal lumen and the diameter of the terminal ileum lumen. The safety of $\mathrm{CO}_{2}$ insufflation was also assessed by measuring the levels of transcutaneous $\mathrm{CO}_{2}$ tension $\left(\mathrm{PtcCO}_{2}\right)$ and evaluating the development of ESD-related complications such as air leaks. 


\section{Materials and methods}

Patients. Between January and December 2009, all consecutive patients undergoing colorectal ESD at Gifu University Hospital (Gifu, Japan), were screened for the present study. Colorectal ESD was indicated for lesions that required endoscopic en bloc resection, despite this technique being difficult to use for endoscopic mucosal resection or polypectomy.

Patients with one or more of the following conditions were excluded: (i) They exhibited chronic pulmonary dysfunction defined as a forced expiratory volume in $1.0 \mathrm{sec} /$ forced vital capacity of $<70 \%$ or a vital capacity of $<80 \%$; (ii) they were unable to understand the consent information required for participation; and/or (iii) they refused to participate in the study. The study protocol was approved by the institutional Ethics Committee of Gifu University Hospital (ethical approval no. 28-104). All eligible individuals provided written informed consent prior to study enrollment. Randomization was conducted using a random number list, and patients were divided into two groups, namely a $\mathrm{CO}_{2}$ insufflation group $\left(\mathrm{CO}_{2}\right.$ group) and an air insufflation group (air group).

ESD procedures and examination schedule for study events prior to and following ESD. ESD was conducted in the afternoon on the day of admission. Prior to inserting the colonoscope, 5.0-10.0 mg diazepam (Cercine ${ }^{\circledR}$; Takeda Pharmaceutical Company, Ltd., Tokyo, Japan), 7.5-15.0 mg pentazocine (Pentagin ${ }^{\circledR}$; Daiichi Sankyo Co., Ltd., Tokyo, Japan) and 12.5-25.0 mg hydroxyzine (Atarax- ${ }^{\circledR}$; Phizer Japan, Inc., Tokyo, Japan) were injected intravenously for induction of anesthesia and analgesia. As necessary, $5.0 \mathrm{mg}$ diazepam or $7.5 \mathrm{mg}$ pentazocine and $12.5 \mathrm{mg}$ hydroxyzine were administered repeatedly for deep sedation; when patients opened their eyes or moved their body, the patients were considered to be out of deep sedation and received the additional injections. The ESD procedures were performed using a colonoscope and water jet (PCF-Q260J; Olympus Medical Systems; Olympus Corporation, Tokyo, Japan). The colorectal lesions were resected using either a DualKnife (KD-650Q) or FlexKnife (KD-630L; both from Olympus Corporation). A $0.4 \%$ high-molecular-weight hyaluronic acid solution containing $0.001 \%$ epinephrine was injected into the submucosal layer to raise the lesion. The mucosal layer around the lesion was cut circumferentially; subsequently, the submucosal layer was directly dissected with the DualKnife or FlexKnife. If possible, the post-ESD ulcer was closed using clips; otherwise, exposed blood vessels were clipped to reduce the risk of active bleeding. Circulation vitals, including systolic and diastolic blood pressures, heart rate and transcutaneous oxygen saturation $\left(\mathrm{SpO}_{2}\right)$ were measured with a bedside monitor (BSM-4101; Nihon Kohden Corporation, Tokyo, Japan) at the start of the procedure, every 5 min during the procedure, and at the end of the procedure. On the second hospital day, blood tests for white blood cell (WBC) count and C-reactive protein (CRP) were performed, and the highest axillary temperature during the total hospital stay was recorded. WBC count was measured with an automated hematology analyzer (XE-2100; Sysmex Corporation, Kobe, Japan) and CRP was measured with an automatic biochemical analyzer (JCA-BM2250; JEOL, Ltd., Tokyo, Japan) with use of a CRP kit (CRP Latex X2 NX ${ }^{\circledast}$;
Denka Seiken Co. Ltd., Tokyo, Japan), according to the manufacturer's instructions.

$\mathrm{CO}_{2}$ insufflation and transcutaneous gas analysis. $\mathrm{CO}_{2}$ was administered using a $\mathrm{CO}_{2}$ regulation unit (OLYMPUS UCRTM; Olympus Corporation). $\mathrm{PtcCO}_{2}$ was continuously measured from the time of insertion of the colonoscope until the end of the procedure by using a $\mathrm{CO}_{2}$ sensor kit (TOSCA measurement system and TOSCA 500 monitor; Linde Medical Sensors Ag, Basel, Switzerland). The low-flow gas tube (MAJ-1742, Olympus Corporation) of the UCR was used for $\mathrm{CO}_{2}$ insufflation, which was set at a constant rate of $1.4 \mathrm{l} / \mathrm{min}$ for all patients, as reported previously (31).

Evaluation of $C T$ examination. CT examination of the abdomen and pelvis was performed immediately following ESD using a 16-MDCT device (LightSpeed 16; GE Healthcare Life Sciences, Little Chalfont, UK) with a fixed tube voltage of $120 \mathrm{kVp}$ and an automatic tube current modulation program (3D mA modulation; GE Healthcare Life Sciences). The operational parameters of the scanner were set to noise index, $10.0 \mathrm{HU}$ at $5 \mathrm{~mm}$ slice thickness; collimation, $1.25 \mathrm{~mm}$; detector configuration, $16 \times 1.25 \mathrm{~mm}$; table feed, $27.5 \mathrm{~mm} /$ rotation; pitch, 1.37:1; field of view, $32 \times 32 \mathrm{~cm}$; gantry rotation time, $0.5 \mathrm{sec}$; acquisition time, $12.7 \mathrm{sec}$. All transverse CT images were reconstructed at $5 \mathrm{~mm}$ section thickness with a standard reconstruction algorithm. CT images were analyzed using Advantage Workstation v4.6 software (GE Healthcare Life Sciences). To evaluate the amount of residual gas in the gastrointestinal tract following ESD, a scan was performed at the level of the ileocecal valve, and the major and minor axes of the cecal lumen and the diameter of the terminal ileum lumen were measured. A small level of focal free air close to the colonic wall of the resected lesion was defined as a transmural air leak and a high level of free air reaching the surface of the liver was defined as free air $(32,33)$.

Definitions of outcome parameters and complications. The operation time was measured from the start of injection into the submucosal layer until the end of the procedure. A diagnosis of perforation was made by direct endoscopic observation during ESD. Post-procedure hemorrhage was diagnosed with clinical evidence of bleeding following ESD, as shown by repetitive bloody bowel discharges that required endoscopic treatment.

Statistical analysis. All the variables in the present study are described as the number of patients (\%) or the median (range). Fisher's exact test was used to compare differences in categorical variables between the two groups when required, and the non-parametric Mann-Whitney U test was used to compare continuous variables. Two-sided $\mathrm{P}<0.05$ was considered to indicate statistically significant differences for all tests. All statistical analyses were performed using JMP v12 (SAS Institute, Inc., Cary, NC, USA).

\section{Results}

Patient and procedure characteristics. A total of 83 patients underwent colorectal ESD during the study period. Among them, 17 patients were excluded due to presentation of chronic 
Table I. Patient and procedure characteristics.

\begin{tabular}{|c|c|c|c|}
\hline Variables & $\mathrm{CO}_{2}$ group $(\mathrm{n}=34)$ & Air group $(n=32)$ & P-value \\
\hline Age, years & $65.0(34.0-87.0)$ & $65.5(34.0-86.0)$ & 0.78 \\
\hline Sex, male/female, $\mathrm{n}$ & $18 / 16$ & $17 / 15$ & 1.00 \\
\hline Location of lesion, $\mathrm{C} / \mathrm{A} / \mathrm{T} / \mathrm{D} / \mathrm{S} / \mathrm{R}, \mathrm{n}$ & $2 / 3 / 7 / 0 / 5 / 17$ & $3 / 6 / 5 / 1 / 5 / 12$ & 0.58 \\
\hline En bloc resection, $\mathrm{n}(\%)$ & $33(97.1)$ & $31(96.9)$ & 1.00 \\
\hline $\begin{array}{l}\text { Histopathological type, } \\
\text { tub1/tub2/adenoma/carcinoid/hyperplastic/ } \\
\text { endocrine carcinoma, n }\end{array}$ & $14 / 1 / 13 / 5 / 0 / 1$ & $11 / 1 / 14 / 5 / 1 / 0$ & 0.71 \\
\hline Histological depth, M/SM, n & $25 / 8$ & $25 / 7$ & 1.00 \\
\hline Histopathologically curative resection, n (\%) & $30(88.2)$ & $31(96.9)$ & 0.36 \\
\hline Tumor size, mm & $30(12-72)$ & $30(12-47)$ & 0.93 \\
\hline Resection size, mm & $23(7-62)$ & $24(3-46)$ & 0.73 \\
\hline Procedure time, $\min$ & $35(10-163)$ & $30(9-94)$ & 0.57 \\
\hline Prophylactic clip closure, n (\%) & $15(44.1)$ & $17(53.1)$ & 0.62 \\
\hline
\end{tabular}

Continuous variables are presented as the median (range). C, cecum; A, ascending colon; T, transverse colon; D, descending colon; S, sigmoid colon; R, rectum; tub, tubular; M, intramucosal; SM, submucosal.

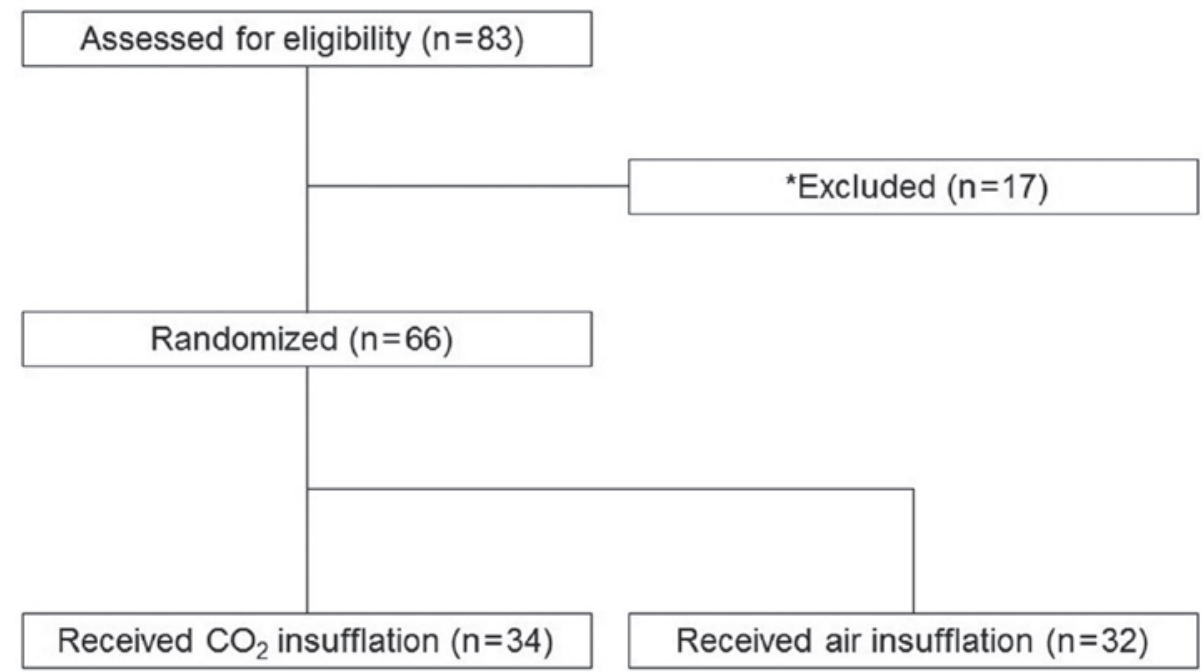

Figure 1. Flow chart of patient enrollment and group allocation process. "All excluded patients $(\mathrm{n}=17)$ presented with chronic pulmonary dysfunction.

pulmonary dysfunction; the remaining 66 patients were enrolled in the present study. The enrolled subjects were randomized into two groups: A total of 34 patients received $\mathrm{CO}_{2}$ insufflation $\left(\mathrm{CO}_{2}\right.$ group) and 32 patients received air insufflation (air group; Fig. 1).

Baseline characteristics and related factors for each group are listed in Table I. The median age was 65.0 (34.0-87.0) years in the $\mathrm{CO}_{2}$ group and 65.5 (34.0-86.0) years in the air group. No significant differences in age, sex, en bloc resection rate, location of the colorectal lesion, histopathological type, tumor size, histological depth, resection size or histopathologically curative resection rate between the groups were identified. The median procedure time was 35 (10-163) and 30 (9-94) min and the rate of clip closure for the post-ESD ulcer was 44.1 and $53.1 \%$ in the $\mathrm{CO}_{2}$ and air groups, respectively; neither of these differed significantly between the groups.
Presence of residual gas in the gastrointestinal tract evaluated by CT examination. Representative CT images of patients in the two groups are presented in Fig. 2. In the air group, marked intestinal dilatation of the cecum and terminal ileum was observed compared with the $\mathrm{CO}_{2}$ group. The findings of the CT examination following ESD are summarized in Table II. The median major (21.8 vs. $56.3 \mathrm{~mm}, \mathrm{P}<0.001)$ and minor (13.4 vs. $36.6 \mathrm{~mm}$, $\mathrm{P}<0.001)$ axes of the cecal lumen at the level of the ileocecal valve were significantly lower in the $\mathrm{CO}_{2}$ group compared with the air group. In addition, the median diameter of the terminal ileum lumen was significantly lower in the $\mathrm{CO}_{2}$ group compared with that in the air group (5.0 vs. $16.4 \mathrm{~mm}, \mathrm{P}<0.001)$. These findings demonstrated the effects of $\mathrm{CO}_{2}$ insufflation on the diminution of residual gas in the bowel following colorectal ESD.

The presence of free air was indicated in 1 patient $(2.9 \%)$ in the $\mathrm{CO}_{2}$ group and 3 patients $(9.4 \%)$ in the air group. 
Table II. Post-ESD computed tomography results.

\begin{tabular}{lllr}
\hline Variables & $\mathrm{CO}_{2}$ group $(\mathrm{n}=34)$ & Air group $(\mathrm{n}=32)$ & P-value \\
\hline Major axis of cecal lumen after ESD, mm & $21.8(6.1-59.0)$ & $56.3(28.9-126.9)$ & $<0.001$ \\
Minor axis of cecal lumen after ESD, mm & $13.4(4.2-39.8)$ & $36.6(11.9-62.3)$ & $<0.001$ \\
Diameter of terminal ileum lumen after ESD, mm & $5.0(0.0-15.9)$ & $16.4(3.5-28.1)$ & $<0.001$ \\
Free air after ESD, $\mathrm{n}(\%)$ & $1(2.9)$ & $3(9.4)$ & 0.340 \\
Transmural air leak after ESD, $\mathrm{n}(\%)$ & $8(23.5)$ & $2(6.3)$ & 0.080
\end{tabular}

Continuous variables are presented as the median (range). ESD, endoscopic submucosal dissection.
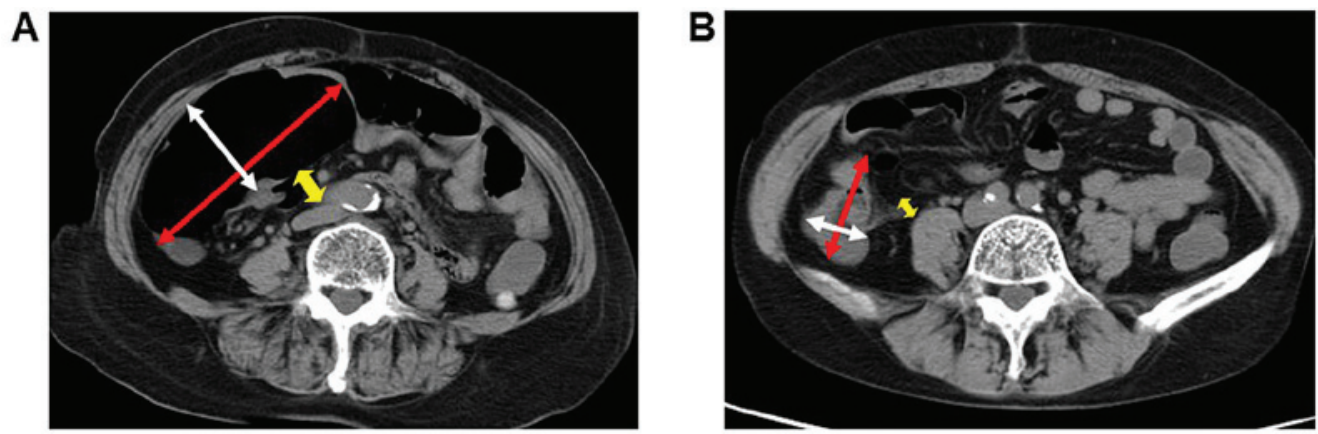

Figure 2. Representative computed tomography images at the level of the ileocecal valve of patients in the (A) air insufflation group and (B) $\mathrm{CO}_{2}$ insufflation group. Marked intestinal dilatation of the cecum and terminal ileum was observed in the air insufflation group, while these dilatations were improved in the $\mathrm{CO}_{2}$ insufflation group. Red two-way arrow, major axis of the cecal lumen; white two-way arrow, minor axis of the cecal lumen; yellow two-way arrow, lumen diameter of the terminal ileum.

Transmural air leak was also observed in 8 patients $(23.5 \%)$ in the $\mathrm{CO}_{2}$ group and 2 patients $(6.3 \%)$ in the air group; however, no significant differences were identified in the incidence rates of these air leaks between the groups.

PtcCO $\mathrm{O}_{2}$ and vital signs prior to and following ESD. The $\mathrm{PtcCO}_{2}$ and vital signs (blood pressure, heart rate and $\mathrm{SpO}_{2}$ ) of patients recorded during ESD are listed in Table III. The median $\mathrm{PtcCO}_{2}$ prior to and following ESD was 38.5 (22.0-51.0) and 46.5 (30.0-58.0) $\mathrm{mmHg}$ in the $\mathrm{CO}_{2}$ group and 40.0 (27.0-48.0) and $47.0(36.0-55.0) \mathrm{mmHg}$ in the air group, respectively; no significant differences in these values between the groups were determined. The median peak $\mathrm{PtcCO}_{2}$ during ESD was 49.0 (34.0-111.0) $\mathrm{mmHg}$ in the $\mathrm{CO}_{2}$ group and 49.0 (40.0-55.0) $\mathrm{mmHg}$ in the air group; no significant difference was observed between these values.

Circulation vitals, including systolic and diastolic blood pressures and heart rate prior to and following ESD, did not differ significantly between the groups. In addition, significant elevation or lowering of blood pressures and heart rate during ESD was not observed in either group. The median minimum $\mathrm{SpO}_{2}$ levels did not differ significantly between the groups, being 98.0 (94.0-100.0) \% in the $\mathrm{CO}_{2}$ group and 98.5 (95.0-100.0) \% in the air group (Table III).

Incidence of post-ESD complications and hospital stay. ESD-related complications and the length of hospital stay are summarized in Table IV. No significant differences were observed in body temperature, incidence of post-ESD hemorrhage or the length of stay between the $\mathrm{CO}_{2}$ and air groups.
Furthermore, no significant differences were identified in serum CRP levels or WBC counts on day 1 after ESD. A patient in the $\mathrm{CO}_{2}$ group presented a complication of perforation during ESD, but the lesion was closed using clips. The patient did not require emergency surgery and was discharged 4 days after ESD. No cases of cardiopulmonary adverse events occurred in either group.

\section{Discussion}

ESD of colorectal tumors can provide clinical benefits as it enables en bloc resection of large superficial neoplasms $(32,34)$. However, one of the problems with this procedure is the severe intraoperative and post-operative abdominal discomfort and distention caused by air infusion (15). $\mathrm{CO}_{2}$ is absorbed by the bowel mucosa approximately 100 times faster than air and is rapidly eliminated through the lungs (35). This may be associated with the superior recovery quality of $\mathrm{CO}_{2}$ insufflation compared with room air insufflation in colonoscopy (36). Therefore, when compared with air insufflation, $\mathrm{CO}_{2}$ insufflation is expected to reduce the volume of residual gas following ESD, which is a primary cause of patient discomfort associated with this procedure, and consequently prevent the development of abdominal symptoms and problems associated with ESD (5,22-30).

The results of the present randomized trial indicated that $\mathrm{CO}_{2}$ insufflation during colorectal ESD significantly reduced the volume of residual bowel gas compared with air insufflation. Several studies have reported the efficacy of $\mathrm{CO}_{2}$ insufflation during various types of endoscopic 
Table III. $\mathrm{PtcCO}_{2}$ and vital signs during ESD.

\begin{tabular}{|c|c|c|c|}
\hline Variables & $\mathrm{CO}_{2}$ group $(\mathrm{n}=34)$ & Air group $(n=32)$ & P-value \\
\hline Baseline $\mathrm{PtCO}_{2}, \mathrm{mmHg}$ & $38.5(22.0-51.0)$ & $40.0(27.0-48.0)$ & 0.13 \\
\hline $\mathrm{PtCO}_{2}$ after $\mathrm{ESD}, \mathrm{mmHg}$ & $46.5(30.0-58.0)$ & $47.0(36.0-55.0)$ & 0.38 \\
\hline Peak $\mathrm{PtCO}_{2}, \mathrm{mmHg}$ & $49.0(34.0-111.0)$ & $49.0(40.0-55.0)$ & 0.95 \\
\hline Baseline systolic blood pressure, $\mathrm{mmHg}$ & $132.5(94.0-187.0)$ & $133.5(98.0-180.0)$ & 0.78 \\
\hline Systolic blood pressure after ESD, $\mathrm{mmHg}$ & $134.5(100.0-180.0)$ & $135.5(85.0-174.0)$ & 0.83 \\
\hline Maximum systolic blood pressure, $\mathrm{mmHg}$ & $150.5(112.0-229.0)$ & $145.0(102.0-182.0)$ & 0.80 \\
\hline Maximum systolic blood pressure elevation value, $\mathrm{mmHg}$ & $3.5(0.0-92.0)$ & $4.5(0.0-42.0)$ & 0.64 \\
\hline Baseline diastolic blood pressure, $\mathrm{mmHg}$ & $74.0(38.0-103.0)$ & $69.5(50.0-95.0)$ & 0.48 \\
\hline Diastolic blood pressure after ESD, $\mathrm{mmHg}$ & $74.5(56.0-104.0)$ & $75.0(45.0-94.0)$ & 0.89 \\
\hline Maximum systolic blood pressure, $\mathrm{mmHg}$ & $84.0(64.0-121.0)$ & $83.0(53.0-112.0)$ & 0.90 \\
\hline Maximum systolic blood pressure elevation value, $\mathrm{mmHg}$ & $7.5(0.0-43.0)$ & $7.5(0.0-34.0)$ & 0.73 \\
\hline Baseline heart rate, $\mathrm{n} / \mathrm{min}$ & $76.5(51.0-125.0)$ & $71.0(50.0-116.0)$ & 0.30 \\
\hline Heart rate after $\mathrm{ESD}, \mathrm{n} / \mathrm{min}$ & $72.0(53.0-97.0)$ & $69.5(53.0-93.0)$ & 0.31 \\
\hline Maximum heart rate, $\mathrm{n} / \mathrm{min}$ & $87.5(61.0-125.0)$ & $80.0(57.0-125.0)$ & 0.07 \\
\hline Maximum heart rate elevation value, $\mathrm{n} / \mathrm{min}$ & $3.5(0.0-48.0)$ & $1.5(0.0-37.0)$ & 0.74 \\
\hline Minimum $\mathrm{SpO}_{2}, \%$ & $98.0(94.0-100.0)$ & $98.5(95.0-100.0)$ & 0.81 \\
\hline
\end{tabular}

Values are presented as the median (range). ESD, endoscopic submucosal dissection; $\mathrm{PtCO}_{2}$, transcutaneous $\mathrm{CO}_{2}$ tension.

Table IV. ESD-related complications and length of hospital stay.

\begin{tabular}{|c|c|c|c|}
\hline Variables & $\mathrm{CO}_{2}$ group $(\mathrm{n}=34)$ & Air group $(n=32)$ & P-value \\
\hline Body temperature, ${ }^{\circ} \mathrm{C}$ & $36.8(36.3-38.5)$ & $36.8(36.3-38.4)$ & 0.94 \\
\hline Post-procedure hemorrhage, n (\%) & $2(5.9)$ & $1(3.1)$ & 1.00 \\
\hline WBC on day 1 after ESD, $\mathrm{n} / \mu \mathrm{l}$ & $6,800(4,220-14,890)$ & $7,500(3,940-18,900)$ & 0.80 \\
\hline CRP on day 1 after ESD, mg/dl & $0.27(0.02-6.17)$ & $0.20(0.02-11.03)$ & 0.98 \\
\hline Perforation, n (\%) & $1(2.9)$ & $0(0)$ & 1.00 \\
\hline Emergency surgery, n (\%) & $0(0)$ & $0(0)$ & 1.00 \\
\hline Hospital stay, days & $3(2-9)$ & $3(2-10)$ & 0.34 \\
\hline
\end{tabular}

Continuous variables are presented as the median (range). CRP, C-reactive protein; ESD, endoscopic submucosal dissection; WBC, white blood cell count.

procedures $(24,25,28,37,38)$. However, few studies have objectively evaluated the level of residual bowel gas following this procedure. Chen et al (39), observed that $\mathrm{CO}_{2}$ insufflation significantly reduced the volume of residual bowel gas compared with air insufflation following colonoscopy by using abdominal radiography. To the best of our knowledge, the present study is the first to objectively evaluate the degree of bowel distention following colorectal ESD using CT examination. The present study identified the median major and minor axes of the cecal lumen at the level of the ileocecal valve to be significantly lower in the $\mathrm{CO}_{2}$ group than in the air group $(\mathrm{P}<0.001)$. In addition, the median diameter of the terminal ileum lumen was significantly lower in the $\mathrm{CO}_{2}$ group than in the air group $(\mathrm{P}<0.001)$. These findings suggest that $\mathrm{CO}_{2}$ insufflation significantly reduced the volume of residual bowel gas compared with air insufflation following colorectal ESD.

In the present study, there was no significant difference in the peak $\mathrm{PtCO}_{2}$, which is a useful marker for evaluating $\mathrm{CO}_{2}$ retention (40), between the $\mathrm{CO}_{2}$ and air insufflation groups.
No marked adverse events, such as $\mathrm{CO}_{2}$ narcosis, air embolism, $\mathrm{SpO}_{2}$ depression or hemodynamic abnormality, occurred in either group. In addition, post-procedure CT demonstrated no significant difference in the incidence of free air or transmural air leak between the groups. $\mathrm{As}^{\mathrm{CO}_{2}}$ insufflation can reduce the volume of residual bowel gas, it may avoid an increase in intra-bowel pressure and improve patient safety. These results suggest that $\mathrm{CO}_{2}$ insufflation during colorectal ESD is a safer alternative to air insufflation.

In the present study, patients with chronic pulmonary dysfunction were excluded, as the safety of $\mathrm{CO}_{2}$ insufflation during colorectal ESD has not been established for such patients. However, a recent study demonstrated that $\mathrm{CO}_{2}$ insufflation during gastric ESD was safe for patients with pulmonary dysfunction under conscious sedation (31). $\mathrm{CO}_{2}$ insufflation during colorectal ESD is also safe for patients with obstructive ventilatory disturbance (41). The number of patients, particularly elderly patients, suffering from complications including chronic pulmonary dysfunction is increasing; 
therefore, a clinical trial that clarifies the safety and efficacy of $\mathrm{CO}_{2}$ insufflation during colorectal ESD in such patients should be conducted.

The present study had a number of limitations. First, the study was a single-center study with a relatively small sample size. Therefore, multi-center studies with larger sample sizes should be performed to confirm the present results. These studies may also be useful for assessing whether $\mathrm{CO}_{2}$ insufflation may reduce the risk of ESD-related complications, such as transmural air leak and perforation, compared with conventional air insufflation. It should be also verified in future studies whether $\mathrm{CO}_{2}$ insufflation relieved abdominal pain and improved the degree of patients' satisfaction. Second, the volume of insufflated gas during the ESD procedure could not be measured. However, it is probable that there was not much difference in the volume of insufflated gas between the $\mathrm{CO}_{2}$ and air groups since the flow volume was the same (1.4 L/min) in both groups and no significant difference was observed in the median procedure time between the groups.

Despite these limitations, it should be emphasized that reduction of the patient's residual gastrointestinal gas following ESD can decrease abdominal fullness; this is associated with a high level of patient satisfaction (35). In conclusion, the present results suggest that $\mathrm{CO}_{2}$ insufflation during colorectal ESD is effective, as it may significantly reduce residual gas in the gastrointestinal tract and therefore increase the satisfaction and comfort of patients who have undergone ESD.

\section{Acknowledgements}

Not applicable.

\section{Funding}

No funding was received.

\section{Availability of data and materials}

The analyzed data sets generated during the study are available from the corresponding author on reasonable request.

\section{Authors' contributions}

TS and HA contributed to the study design, acquisition and interpretation of data, and in the writing of the manuscript; NO and JT acquired the data; MK and TI analyzed and interpreted the data; MS wrote the manuscript and approved the final contents of the manuscript. The final version of the manuscript has been read and approved by all authors.

\section{Ethics approval and consent to participate}

The study protocol was approved by the institutional ethics committee of Gifu University Hospital (ethical approval code: 28-104). All eligible individuals provided written informed consent prior to study enrollment.

\section{Consent for publication}

Not applicable.

\section{Competing interests}

The authors declare no competing interests.

\section{References}

1. Zauber AG, Winawer SJ, O'Brien MJ, Lansdorp-Vogelaar I, van Ballegooijen M, Hankey BF, Shi W, Bond JH, Schapiro M, Panish JF, et al: Colonoscopic polypectomy and long-term prevention of colorectal-cancer deaths. N Engl J Med 366: 687-696, 2012.

2. Rex DK,Johnson DA, Lieberman DA, Burt RW and Sonnenberg A: American College of Gastroenterology: Colorectal cancer prevention 2000: Screening recommendations of the American College of Gastroenterology. Am J Gastroenterol 95: 868-877, 2000.

3. Saito Y, Kawano H, Takeuchi Y, Ohata K, Oka S, Hotta K, Okamoto K, Homma K, Uraoka T, Hisabe T, et al: Current status of colorectal endoscopic submucosal dissection in Japan and other Asian countries: Progressing towards technical standardization. Dig Endosc 24 (Suppl 1): 67-72, 2012.

4. Fujishiro M: Endoscopic submucosal dissection for colorectal neoplasms. World J Gastrointest Endosc 1: 32-38, 2009.

5. Saito Y, Uraoka T, Yamaguchi Y, Hotta K, Sakamoto N, Ikematsu H, Fukuzawa M, Kobayashi N, Nasu J, Michida T, et al: A prospective, multicenter study of 1111 colorectal endoscopic submucosal dissections (with video). Gastrointest Endosc 72: 1217-1225, 2010.

6. Morley AP, Lau JY and Young RJ: Tension pneumothorax complicating a perforation of a duodenal ulcer during ERCP with endoscopic sphincterotomy. Endoscopy 29: 332, 1997.

7. Katzgraber F, Glenewinkel F, Fischler S and Rittner C: Mechanism of fatal air embolism after gastrointestinal endoscopy. Int J Legal Med 111: 154-156, 1998.

8. Rai A and Iftikhar S: Tension pneumothorax complicating diagnostic upper endoscopy: A case report. Am J Gastroenterol 94: 845-847, 1999.

9. Nayagam J, Ho KM and Liang J: Fatal systemic air embolism during endoscopic retrograde cholangio-pancreatography. Anaesth Intensive Care 32: 260-264, 2004.

10. Green BT and Tendler DA: Cerebral air embolism during upper endoscopy: Case report and review. Gastrointest Endosc 61: 620-623, 2005.

11. Stabile L, Cigada M, Stillittano D, Morandi E, Zaffroni M, Rossi G and Lapichino G: Fatal cerebral air embolism after endoscopic retrograde cholangiopancreatography. Acta Anaesthesiol Scand 50: 648-649, 2006.

12. Bisceglia M, Simeone A, Forlano R, Andriulli A and Pilotto A: Fatal systemic venous air embolism during endoscopic retrograde cholangiopancreatography. Adv Anat Pathol 16: 255-262, 2009.

13. Finsterer J, Stöllberger C and Bastovansky A: Cardiac and cerebral air embolism from endoscopic retrograde cholangio-pancreatography. Eur J Gastroenterol Hepatol 22: 1157-1162, 2010.

14. van Boxel GI, Hommers CE, Dash I, Goodman AJ, Green J and Orme RM: Myocardial and cerebral infarction due to massive air embolism following endoscopic retrograde cholangiopancreatography (ERCP). Endoscopy 42 (Suppl 2): E80-E81, 2010.

15. Saito Y, Uraoka T, Matsuda T, Emura F, Ikehara H, Mashimo Y, Kikuchi T, Kozu T and Saito D: A pilot study to assess the safety and efficacy of carbon dioxide insufflation during colorectal endoscopic submucosal dissection with the patient under conscious sedation. Gastrointest Endosc 65: 537-542, 2007.

16. Nonaka S, Saito Y, Takisawa H, Kim Y, Kikuchi T and Oda I: Safety of carbon dioxide insufflation for upper gastrointestinal tract endoscopic treatment of patients under deep sedation. Surg Endosc 24: 1638-1645, 2010.

17. Maeda Y, Hirasawa D, Fujita N, Obana T, Sugawara T, Ohira T, Harada Y, Yamagata T, Suzuki K, Koike Y, et al: A prospective, randomized, double-blind, controlled trial on the efficacy of carbon dioxide insufflation in gastric endoscopic submucosal dissection. Endoscopy 45: 335-341, 2013.

18. Kikuchi T, Fu KI, Saito Y, Uraoka T, Fukuzawa M, Fukunaga S, Sakamoto T, Nakajima T and Matsuda T: Transcutaneous monitoring of partial pressure of carbon dioxide during endoscopic submucosal dissection of early colorectal neoplasia with carbon dioxide insufflation: A prospective study. Surg Endosc 24: 2231-2235, 2010. 
19. Suzuki T, Minami H, Komatsu T, Masusda R, Kobayashi Y, Sakamoto A, Sato Y, Inoue H and Serada K: Prolonged carbon dioxide insufflation under general anesthesia for endoscopic submucosal dissection. Endoscopy 42: 1021-1029, 2010.

20. Kim SY, Chung JW, Park DK, Kwon KA, Kim KO and Kim YJ: Efficacy of carbon dioxide insufflation during gastric endoscopic submucosal dissection: A randomized, double-blind, controlled, prospective study. Gastrointest Endosc 82: 1018-1024, 2015.

21. Li X, Dong H, Zhang Y and Zhang G: $\mathrm{CO}_{2}$ insufflation versus air insufflation for endoscopic submucosal dissection: A meta-analysis of randomized controlled trials. PLoS One 12 e0177909, 2017.

22. Hussein AM, Bartram CI and Williams CB: Carbon dioxide insufflation for more comfortable colonoscopy. Gastrointest Endosc 30: 68-70, 1984.

23. Stevenson GW, Wilson JA, Wilkinson J, Norman G and Goodacre RL: Pain following colonoscopy: Elimination with carbon dioxide. Gastrointest Endosc 38: 564-567, 1992.

24. Church J and Delaney C: Randomized, controlled trial of carbon dioxide insufflation during colonoscopy. Dis Colon Rectum 46: 322-326, 2003.

25. Sumanac K, Zealley I, Fox BM, Rawlinson J, Salena B, Marshall JK, Stevenson GW and Hunt RH: Minimizing postcolonoscopy abdominal pain by using $\mathrm{CO}_{2}$ insufflation: $\mathrm{A}$ prospective, randomized, double blind, controlled trial evaluating a new commercially available $\mathrm{CO}_{2}$ delivery system. Gastrointest Endosc 56: 190-194, 2002.

26. Rogers BH: The safety of carbon dioxide insufflation during colonoscopic electrosurgical polypectomy. Gastrointest Endosc 20: 115-117, 1974.

27. Bretthauer M, Lynge AB, Thiis-Evensen E, Hoff G, Fausa O and Aabakken L: Carbon dioxide insufflation in colonoscopy: Safe and effective in sedated patients. Endoscopy 37: 706-709, 2005.

28. Bretthauer M, Thiis-Evensen E, Huppertz-Hauss G, Gisselsson L, Grotmol T, Skovlund E and Hoff G: NORCCAP (Norwegian colorectal cancer prevention): A randomised trial to assess the safety and efficacy of carbon dioxide versus air insufflation in colonoscopy. Gut 50: 604-607, 2002.

29. Nakajima K, Lee SW, Sonoda T and Milsom JW: Intraoperative carbon dioxide colonoscopy: A safe insufflation alternative for locating colonic lesions during laparoscopic surgery. Surg Endosc 19: 321-325, 2005.

30. Wu $\mathrm{J}$ and $\mathrm{Hu} \mathrm{B}$ : The role of carbon dioxide insufflation in colonoscopy: A systematic review and meta-analysis. Endoscopy 44: 128-136, 2012.

31. Takada J, Araki H, Onogi F, Nakanishi T, Kubota M, Ibuka T, Shimizu M and Moriwaki H: Safety of carbon dioxide insufflation during gastric endoscopic submucosal dissection in patients with pulmonary dysfunction under conscious sedation. Surg Endosc 29: 1963-1969, 2015.

32. Tamegai Y, Saito Y, Masaki N, Hinohara C, Oshima T, Kogure E, Liu Y, Uemura N and Saito K: Endoscopic submucosal dissection: A safe technique for colorectal tumors. Endoscopy 39: 418-422, 2007.
33. Coriat R, Leblanc S, Pommaret E, Chryssostalis A, Prat F and Chaussade S: Transmural air leak following endoscopic submucosal dissection: A non-useful computed tomography finding. Endoscopy 42: 1117, author reply 1118, 2010.

34. Terasaki M, Tanaka S, Oka S, Nakadoi K, Takata S, Kanao H, Yoshida S and Chayama K: Clinical outcomes of endoscopic submucosal dissection and endoscopic mucosal resection for laterally spreading tumors larger than $20 \mathrm{~mm}$. J Gastroenterol Hepatol 27: 734-740, 2012.

35. Saltzman HA and Sieker HO: Intestinal response to changing gaseous environments: Normobaric and hyperbaric observations. Ann N Y Acad Sci 150 (1 Gastrointesti): 31-39, 1968.

36. Wang WL, Wu ZH, Sun Q, Wei JF, Chen XF, Zhou DK, Zhou L, Xie HY and Zheng SS: Meta-analysis: The use of carbon dioxide insufflation vs. room air insufflation for gastrointestinal endoscopy. Aliment Pharmacol Ther 35: 1145-1154, 2012.

37. Dellon ES, Velayudham A, Clarke BW, Isaacs KL, Gangarosa LM, Galanko JA and Grimm IS: A randomized, controlled, double-blind trial of air insufflation versus carbon dioxide insufflation during ERCP. Gastrointest Endosc 72: 68-77, 2010.

38. Hirai F, Beppu T, Nishimura T, Takatsu N, Ashizuka S, Seki T, Hisabe T, Nagahama T, Yao K, Matsui T, et al: Carbon dioxide insufflation compared with air insufflation in double-balloon enteroscopy: A prospective, randomized, double-blind trial. Gastrointest Endosc 73: 743-749, 2011

39. Chen SW, Hui CK, Chang JJ, Lee TS, Chan SC, Chien $\mathrm{CH}$, $\mathrm{Hu}$ CC, Lin CL, Chen LW, Liu CJ, et al: Carbon dioxide insufflation during colonoscopy can significantly decrease post-interventional abdominal discomfort in deeply sedated patients: A prospective, randomized, double-blinded, controlled trial. J Gastroenterol Hepatol 31: 808-813, 2016.

40. Chhajed PN, Kaegi B, Rajasekaran R and Tamm M: Detection of hypoventilation during thoracoscopy: Combined cutaneous carbon dioxide tension and oximetry monitoring with a new digital sensor. Chest 127: 585-588, 2005.

41. Yoshida M, Imai K, Hotta K, Yamaguchi Y, Tanaka M, Kakushima N, Takizawa K, Matsubayashi H and Ono H: Carbon dioxide insufflation during colorectal endoscopic submucosal dissection for patients with obstructive ventilatory disturbance. Int J Colorectal Dis 29: 365-371, 2014 